EPJ Web of Conferences 110,01043 (2016)

DOI: $10.1051 /$ epjconf/201611001043

C) Owned by the authors, published by EDP Sciences, 2016

\title{
NUMERICAL MODELING OF CONJUGATE THERMOGRAVITATIONAL CONVECTION IN A CLOSED SYSTEM WITH A RADIANT ENERGY SOURCE IN CONDITIONS OF CONVECTIVE-RADIATIVE HEAT EXCHANGE AT THE EXTERNAL BOUNDARY
}

\author{
Alexander $\mathrm{Nee}^{1}$ \\ ${ }^{1}$ National Research Tomsk Polytechnic University, 634050 Tomsk, Russia
}

\begin{abstract}
Mathematical modeling of conjugate natural convection in a closed rectangular cavity with a radiant energy source in conditions of convective-radiative heat exchange at the external boundary was conducted. The radiant energy distribution was set by the Lambert's law. Conduction and convection processes analysis showed that the air masses flow pattern is modified slightly over the time. The temperature increases in the gas cavity, despite the heat removal from the one of the external boundary. According to the results of the integral heat transfer analysis were established that the average Nusselt number $\left(N u_{a v}\right)$ increasing occurs up to $\tau=200$ (dimensionless time). Further $N u_{a v}$ has changed insignificantly due to the temperature field equalization near the interfaces "gas - wall".
\end{abstract}

\section{Introduction}

Well-known approaches [1, 2] for analyzing the thermal regimes of the areas with infrared emitters (IE) are based on the heat balance equation solution of the premises. Such models are quite simple to implement, but have some limitations (convective heating and the air masses flow pattern, heat-retaining properties of the enclosure structures and the thermal state of the radiant heat source do not taking into account). At the same time, conjugate heat transfer models [3,4], which are based on the NavierStokes and energy equations solution, contribute to far more detailed analysis of the conduction, convection and radiation processes.

In order to study the basic laws of heat transfer in the cavities, which are filled by gas and limited by heat-conducting finite thickness walls, with a radiant energy source suggested a conjugate heat exchange model $[5,6]$. An approach [5,6] takes into account air masses convective heating and the influence of enclosure structures heat-retaining properties on the heat transfer intensity. Problem formulation [5,6] assumed that the heat exchange at the external boundaries of the solution domain was absent. But in real radiant heating sources operating conditions, temperature difference between the outside air and the emitter's surface can reach hundreds of Celsius degrees. The thermal regime analysis of a closed system with a local radiant energy source in conditions of convective - radiative heat exchange at the one of the external boundaries is of interest.

The aim of this study is numerical analysis of conjugate thermogravitational convection in a closed system with a radiant energy source in conditions of convective-radiative heat exchange at the one of the external boundaries.

\section{Problem formulation and solution method}

Figure 1 shows the solution domain of the conductive - convective heat transfer boundary value problem. Analyzed object consists of 6 similar rectangles. The infrared emitter 3 was located under the upper horizontal interface "gas - wall". The air is considered as a completely transparent environment for heat radiation. The radiant energy distribution along the lower horizontal and vertical interfaces "gas - wall" was set in accordance with Lambert's law [7]. The temperature of the infrared emitter surface was assumed to be constant in time. The flow regime of gas (Boussinesq model) was considered as laminar. Thermal properties of air and enclosure structures did not depend on temperature.

The conductive-convective heat transfer process under study in conditions of the radiant energy source operating is described by unsteady Navier-Stokes (in the transformed variables "vorticity - stream function") and energy equations. In dimensionless variables "vorticity - stream function - temperature" are as follows [3,5]: for gas:

${ }^{1}$ Corresponding author: nee_alexander@mail.ru 


\section{EPJ Web of Conferences}

$$
\begin{gathered}
\frac{\partial \Omega}{\partial \tau}+\frac{\partial \Psi}{\partial Y} \frac{\partial \Omega}{\partial X}-\frac{\partial \Psi}{\partial X} \frac{\partial \Omega}{\partial Y}=\sqrt{\frac{\operatorname{Pr}}{\mathrm{Ra}}} \cdot\left(\frac{\partial^{2} \Omega}{\partial X^{2}}+\frac{\partial^{2} \Omega}{\partial Y^{2}}\right)+\frac{\partial \Theta_{1}}{\partial X}, \\
\frac{\partial^{2} \Psi}{\partial X^{2}}+\frac{\partial^{2} \Psi}{\partial Y^{2}}=-\Omega,
\end{gathered}
$$

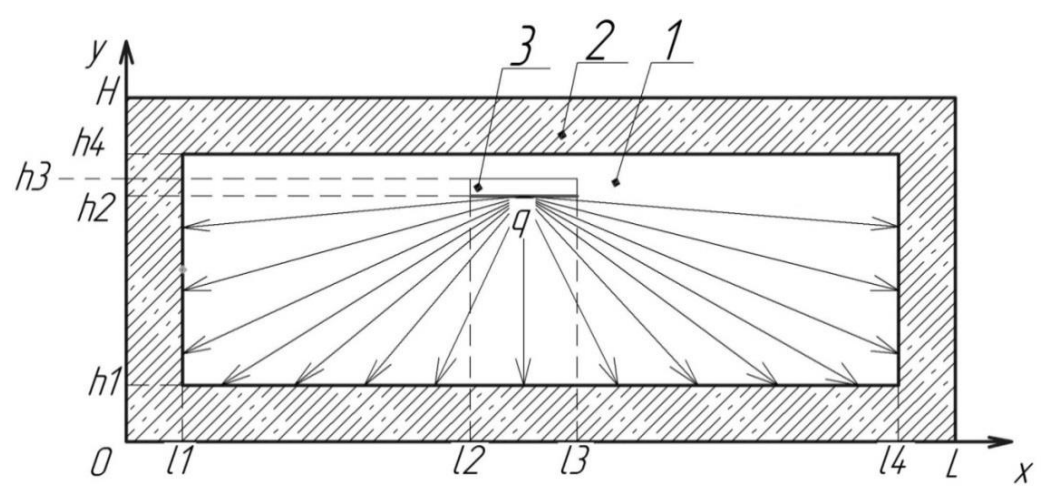

Figure 1. Solution domain: 1 - air; 2 - thermally conductive walls; 3 - gas infrared emitter (symbolic notation).

$$
\frac{\partial \Theta_{1}}{\partial \tau}+\frac{\partial \Psi}{\partial Y} \frac{\partial \Theta_{1}}{\partial X}-\frac{\partial \Psi}{\partial X} \frac{\partial \Theta_{1}}{\partial Y}=\frac{1}{\sqrt{\operatorname{Ra} \cdot \operatorname{Pr}}} \cdot\left(\frac{\partial^{2} \Theta_{1}}{\partial X^{2}}+\frac{\partial^{2} \Theta_{1}}{\partial Y^{2}}\right)
$$

for enclosures:

$$
\frac{\partial \Theta_{2}}{\partial F_{2}}=\frac{\partial^{2} \Theta_{2}}{\partial X^{2}}+\frac{\partial^{2} \Theta_{2}}{\partial Y^{2}}
$$

for infrared emitter:

$$
\frac{\partial \Theta_{3}}{\partial F_{3}}=\frac{\partial^{2} \Theta_{3}}{\partial X^{2}}+\frac{\partial^{2} \Theta_{3}}{\partial Y^{2}} .
$$

The initial conditions for the equations (1) - (5) are as follows:

$$
\Psi=\Omega=\Theta=0 .
$$

Boundary conditions for equations (1) - (5) are as follows:

at the surface of the radiant heat source:

$$
\Theta=1 \text {. }
$$

at the external boundaries of the solution domain:

$$
\frac{\partial \Theta_{2}(X, Y, \tau)}{\partial n}=0
$$

at the boundary $\mathrm{y}=\mathrm{H}, 0<\mathrm{x}<\mathrm{L}$ :

$$
\frac{\partial \Theta}{\partial Y}=B i \cdot\left(\Theta-\Theta_{e}\right)+\mathrm{Sk} \cdot\left[\left(\Theta+\frac{T_{0}}{T_{h}-T_{0}}\right)^{4}-\left(\frac{T_{e}}{T_{h}-T_{0}}\right)^{4}\right]
$$

at the interfaces "gas - wall" parallel to the axis X: 


$$
\Psi=0, \frac{\partial \Psi}{\partial \mathrm{Y}}=0,\left\{\begin{array}{l}
\Theta_{\mathrm{i}}=\Theta_{\mathrm{j}}, \\
\frac{\partial \Theta_{\mathrm{i}}}{\partial \mathrm{Y}}=\frac{\lambda_{\mathrm{j}}}{\lambda_{\mathrm{i}}} \cdot \frac{\partial \Theta_{\mathrm{i}}}{\partial \mathrm{Y}}+\mathrm{Ki},
\end{array} \text { where } \mid \begin{array}{l}
\mathrm{i}=\overline{1,3} \\
\mathrm{j}=\overline{1,3}
\end{array}\right.
$$

at the interfaces "gas - wall" parallel to the axis Y:

$$
\Psi=0, \frac{\partial \Psi}{\partial X}=0,\left\{\begin{array}{l}
\Theta_{i}=\Theta_{j}, \\
\frac{\partial \Theta_{i}}{\partial X}=\frac{\lambda_{j}}{\lambda_{i}} \cdot \frac{\partial \Theta_{i}}{\partial X}+K i,
\end{array} \text { where } \mid \begin{array}{l}
i=\overline{1,3} \\
j=\overline{1,3}
\end{array} .\right.
$$

where $F_{O}$ - Fourier number; $R a$ - Rayleigh number; $K i$-Kirpichev number; Pr- Prandtl number; Sk - radiative Stark number; $\lambda$ - coefficient of thermal conductivity, $\mathrm{W} /(\mathrm{m} \cdot \mathrm{K}) ; \mathrm{X}, \mathrm{Y}$ - dimensionless coordinates; Indices: 1, 2,3 - elements of construction (Figure 1).

Formulated problem (1) - (5) with the corresponding initial (6) and boundary conditions (7) - (11) has been solved by finite difference method on a uniform grid $(151 \times 151)$, as in $[3,6,8]$. For approximation of the partial derivatives differential equations were used alternating direction implicit scheme [9]. Obtained one-dimensional difference analogues were solved by the sweep method [10].

The used algorithm and solution method were tested on the model problem of the natural convection [11, 12] in a closed square cavity in order to evaluate the validity of the numerical simulation. Test results are shown in table 1.Table 1. Comparison of the average Nusselt numbers.

Table 1. Comparison of the average Nusselt numbers.

\begin{tabular}{|c|c|c|c|}
\hline \multirow{2}{*}{ Ra } & \multirow{2}{*}{ This study $($ grid $81 \times 81)$} & \multicolumn{2}{|c|}{$\begin{array}{l}\text { The results of another } \\
\text { authors }\end{array}$} \\
\cline { 3 - 4 } & & {$[11]$} & {$[12]$} \\
\hline $10^{3}$ & 1,089 & 1,121 & 1,108 \\
\hline $10^{4}$ & 2,205 & 2,286 & 2,201 \\
\hline $10^{5}$ & 4,442 & 4,546 & 4,430 \\
\hline
\end{tabular}

Based on the analysis of $N u_{a v}$ values, which are presented in the Table 1, it can be concluded that using algorithm and solution method are able to work.

\section{Results and discussion}

Numerical modeling conducted for the following values of the dimensionless parameters: $R a=10^{6}, \operatorname{Pr}=0,71,0<K i \leq 50, \mathrm{Ki}=1$. Typical results of the boundary value problem solution in dynamics are shown in figure 2
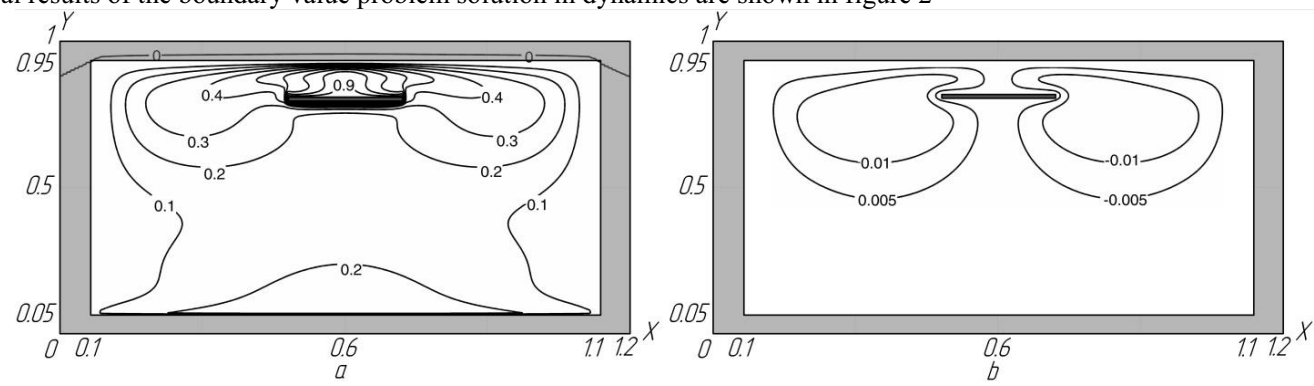

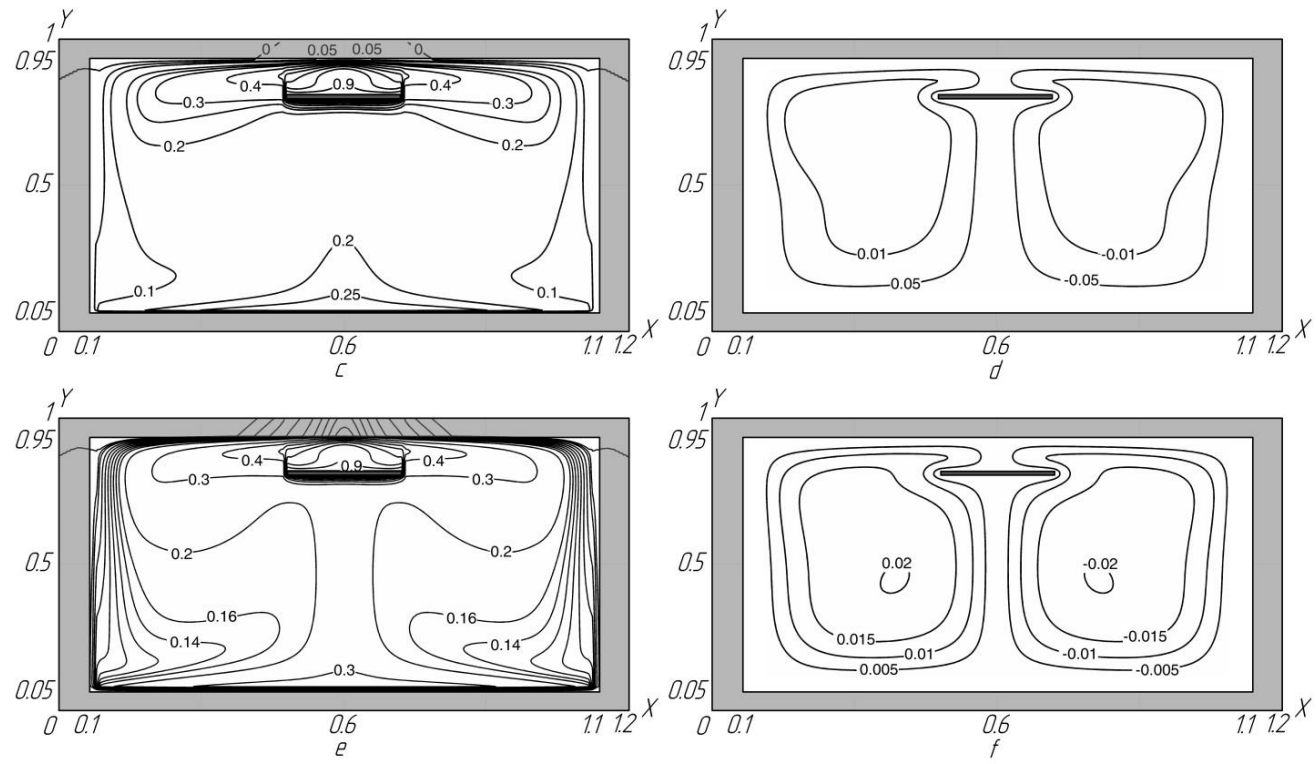

Figure 2. Isolines of temperatures (a, c, e) and the stream functions (b, d, f) at: $a, b) \tau=50 ; c, d) \tau=300$; $e, f) \tau=1000$.

The basic differential heat transfer parameters formation in conditions of natural convection over the time is presented in figure 2. It was found that air masses heating was carried out in the conduction mode near the infrared emitter and due to natural convection from surfaces, which were heated by radiant flux. Presented temperature fields (fig. 2 a, c, e) illustrate the unsteady nature of the conjugate heat transfer process under study. The air temperature near the bottom horizontal and vertical interfaces "gas - wall" increases with time, which is responsible for a continuous energy supply to these surfaces. Two large-scale convection cells are formed in the gas cavity. Air velocity is raised with increasing the time, whereof the value of the stream isolines (fig. 2 b, d, f) are evidenced. Impact of convective-radiative heat exchange at the one of the external boundaries on the conjugate heat transfer nature in the analyzed area is visualized in intense heating of the top horizontal wall (fig. 2 e). As this takes place the temperature does not decrease, which is responsible for, on the one hand, the relatively large thickness of the walls, which limited the gas cavity, on the other, a low value of thermal conductivity coefficient of the enclosure structures.

Figure 3 shows the temperature distribution in the characteristic sections according along the axis $\mathrm{Y}$.
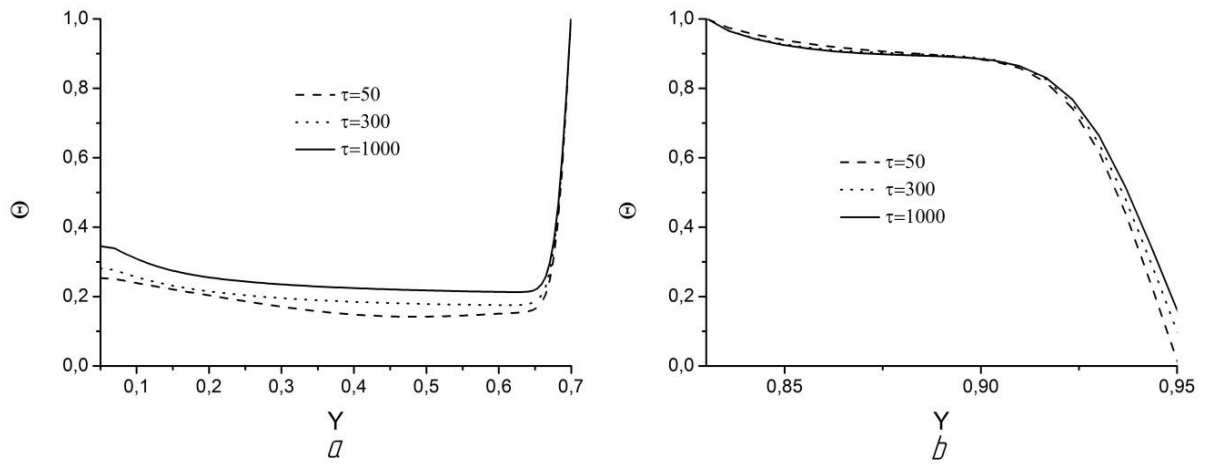

Figure 3. The temperature distribution along the axis $\mathrm{Y}$ in the cross section $\mathrm{X}=0.6$.

Obtained distributions (fig. 3) in dynamics illustrate significant heterogeneity of temperature fields which are formed during infrared emitters operating. It is clearly seen that $\Theta$ of the bottom (fig. 3a) and the top (fig. $3 \mathrm{~b}$ ) the horizontal interfaces "gas wall" rises with increasing the time. Quasi-stationary mode is observed in the areas of $0,65<\mathrm{Y}<0,7$ (fig. 3a) and $0,8<\mathrm{Y}<95$ (fig. $3 \mathrm{~b}$ ) as this takes place, what is connected with heat transfer by conduction of the gas near the radiant energy source .

Integral analysis is carried out by using the average Nusselt number in order to estimate the convective heat transfer intensity in conditions of infrared emitters operating. Dimensionless heat exchange coefficient at the top ( $\left.N u_{a v 1}\right)$ and bottom ( $\left.N u_{a v 2}\right)$ horizontal and the right $\left(N u_{a v 3}\right)$ vertical interfaces "gas - wall" is determined [4] are as follows: 


$$
N u_{a v 1}=\int_{0,1}^{1,1}\left|\frac{\partial \Theta}{\partial Y}\right|_{Y=0,95} d X ; \quad N u_{a v 2}=\int_{0,1}^{1,1}\left|\frac{\partial \Theta}{\partial Y}\right|_{Y=0,05} d X ; \quad N u_{a v 3}=\frac{1}{0,9} \int_{0,05}^{0,95}\left|\frac{\partial \Theta}{\partial X}\right|_{Y=1,1} d Y
$$

Figure 4 shows the dependences of the average integral Nusselt number versus dimensionless time.

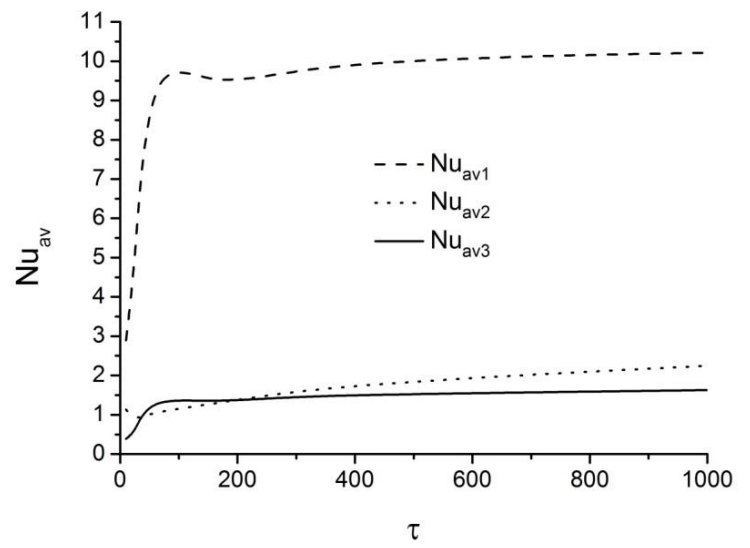

Figure 4. Dependencies $N u_{a v}$ versus $\tau$.

It is clearly seen that the changes in the average Nusselt numbers are taken place before $\tau=200$. Subsequently, the analyzed criterion varies slightly. It should be noted that a significantly greater value of the dimensionless heat exchange coefficient at the top horizontal interface "gas - wall" is explained by heat removal through this region $0.95<\mathrm{Y}<1,0<\mathrm{X}<1,2$ (Fig. 2) due to convective - radiative heat transfer at the boundary $\mathrm{Y}=1,0<\mathrm{X}<1,2$.

\section{Conclusion}

The conjugate heat transfer basic laws are obtained according to the numerical modeling results of heat exchange in a closed rectangular area in conditions of the radiant energy source operating. The impact scale of the convective-radiative heat exchange at the interface $\mathrm{Y}=1,0<\mathrm{X}<1,2$ on the intensity of heat transfer through the top horizontal wall is established. The possibility of using approach $[5,6]$ at investigation of jointly proceeding processes of conduction, convection and radiation in systems with local radiation energy sources is shown.

\section{Acknowledgments}

The author of this paper is very grateful to his scientific advisor Kuznetsov G.V. for significant help in problem formulation and results discussion.

The work was performed as part of research Goszadaniya "Science” №13.1339.2014 / K (code Federal Target Scientific and Technical Program 2.1410.2014). The reported investigation was supported by grant of State Task "Nauka" №13.1339.2014/K (code of the Federal Target Scientific and Technical Program no. 2.1410.2014).

\section{References}

1. V. V. Buhmirov, S. A. Krupennikov, Yu. S. Solnyshkova, Her. of Ivan. St. Pow. Un. 2 (2009)

2. V. V. Buhmirov, S. A. Krupennikov, Yu. S. Solnyshkova, Her. of Ivan. St. Pow. Un. 4 (2010)

3. G.V Kuznetsov, M.A. Sheremet, T. and A. 16, 1 (2009)

4. G.V. Kuznetsov and M.A. Sheremet, Int. J. of Heat and Mass Tr., 52, 1 - 2 ( 2009)

5. G.V. Kuznetsov, V.I. Maksimov, T.A. Nagornova, N.I. Kurilenko, G. Ya. Mamontov, J. of Engin. Ph. and Thermoph. 86, $3(2013)$

6. G.V. Kuznetsov, T.A. Nagornova, A.E. Ni, J. of Engin. Ph. and Thermoph. 88, 1 (2015)

7. M.F. Modest Radiative Heat Transfer 3rd Edition. - Elsevier, 2013.

8. G.V. Kuznetsov, P.A. Strizhak J. of Engin. Thermoph. 17, 3 (2008)

9. A.A. Samarskii, The Theory of Difference Schemes [in Russian](Nauka, Moscow, 1977)

10. P. J. Roache, Computational Fluid Dynamics (Hermosa Publishers, Albuquerque, NM, USA, 1976)

11. H.N. Dixit, V. Babu Int. J. H. M. Tr. 49 (2006)

12. H. Sajjadi, R. Kefayatib, Therm. Sc. 19, 1 (2015) 